Li Qi, W. Robert J. Funnell, \& Sam J. Daniel

\title{
A nonlinear finite-element model of the newborn middle ear
}

Published in:

Journal of the Acoustical Society of America, 124(1), July 2008, pp. 337347

Copyright (2008) Acoustical Society of America. This article may be downloaded for personal use only. Any other use requires prior permission of the author and the Acoustical Society of America.

doi:10.1121/1.2920956

http://scitation.aip.org/content/asa/journal/jasa/124/1/10.1121/1.2920956 


\title{
A nonlinear finite-element model of the newborn middle ear
}

\author{
Li Qi \\ Department of BioMedical Engineering, McGill University, Montréal H3A 2B4, Canada \\ W. Robert J. Funnell ${ }^{\text {a) }}$ \\ Departments of BioMedical Engineering and Otolaryngology, McGill University, Montréal H3A 2B4, \\ Canada \\ Sam J. Daniel \\ Department of Otolaryngology, McGill University, Montréal H3H 1P3, Canada
}

(Received 27 December 2007; revised 10 April 2008; accepted 12 April 2008)

\begin{abstract}
A three-dimensional static nonlinear finite-element model of a 22-day-old newborn middle ear is presented. The model includes the tympanic membrane (TM), malleus, incus, and two ligaments. The effects of the middle-ear cavity are taken into account indirectly. The geometry is based on a computed-tomography scan and on the published literature, supplemented by histology. A nonlinear hyperelastic constitutive law is applied to model large deformations. The middle-ear cavity and the Young's modulus of the TM have significant effects on TM volume displacements. The TM volume displacement and its nonlinearity and asymmetry increase as the middle-ear cavity volume increases. The effects of the Young's moduli of the ligaments and ossicles are found to be small. The simulated TM volume changes do not reach a plateau when the pressure is varied to either $-3 \mathrm{kPa}$ or $+3 \mathrm{kPa}$, which is consistent with the nonflat tails often found in tympanograms in newborns. The simulated TM volume displacements, by themselves and also together with previous ear-canal model results, are compared with equivalent-volume differences derived from tympanometric measurements in newborns. The results suggest that the canal-wall volume displacement makes a major contribution to the total canal volume change, and may be larger than the TM volume displacement. (C) 2008 Acoustical Society of America. [DOI: 10.1121/1.2920956]
\end{abstract}

PACS number(s): 43.64.Bt, 43.64.Ha [BLM]

Pages: $337-347$

\section{INTRODUCTION}

High static pressures are used in several types of hearing examination, including admittance tympanometry (e.g., Shanks and Lilly, 1981; Margolis and Shanks, 1991; Keefe et al., 1993), reflectance tympanometry (e.g., Keefe and Levi, 1996; Margolis et al., 2001; Sanford and Feeney, 2007), pressure-volume measurement (e.g., Elner et al., 1971; Gaihede, 1999), and pressurized acoustical transfer function measurement (Keefe and Simmons, 2003). Understanding the mechanical response of the middle ear to high static pressures is important for understanding the results of such measurements.

The mechanical deformations of the tympanic membrane (TM) in response to high static pressures have been experimentally studied in human adult (Elner et al., 1971; Dirckx and Decraemer 1991; Dirckx and Decraemer 1992; Vorwerk et al., 1999; Gaihede, 1999) and in animals (von Unge et al., 1993; Dirckx et al., 1997; Dirckx et al., 1998; Dirckx and Decraemer, 2001; Larsson et al., 2001; Lee and Rosowski, 2001; Rosowski and Lee, 2002; Ladak et al., 2004; Larsson et al., 2005; Dirckx et al., 2006). The TM in response to high static pressures has also been studied by the nonlinear finite-element method (Ladak et al., 2006; Cheng

\footnotetext{
a) Author to whom correspondence should be addressed. Electronic mail: robert.funnell@mcgill.ca
}

et al., 2007). To date, neither mechanical measurements nor modeling studies have been reported for the newborn middle ear.

Understanding the volume displacement of the newborn TM in response to high static pressures is important for interpreting pressurized measurements in newborn hearing screening and diagnosis. As we have discussed in more detail in a previous paper (Qi et al., 2006), it is important to be able to distinguish conductive hearing loss from sensorineural hearing loss soon after birth but the usual clinical test, tympanometry, gives quite different results in newborns than it does in adults. For example, some newborns with confirmed middle-ear effusion exhibit normal-appearing single-peak tympanograms (e.g., Paradise et al., 1976; Meyer et al., 1997). This is because the external ear and middle ear in newborns differ significantly from those in adults. For one thing, unlike the adult ear canal, of which the inner two thirds are bone, the entire newborn ear canal is composed of soft tissue. It is thus difficult to differentiate the clinically interesting TM volume displacement from the associated canal-wall volume displacement in response to high static pressures (as used in tympanometry). Holte et al. (1990) first measured newborn canal-wall displacement in response to static tympanometric pressures $( \pm 2.5$ to $\pm 3 \mathrm{kPa})$ using video otoscopy. They found, with considerable variability, that the diameter of the ear canal can change by up to $70 \%$ in newborns at birth. We recently presented a nonlinear newborn ear-canal model, which for the first time simulated the 


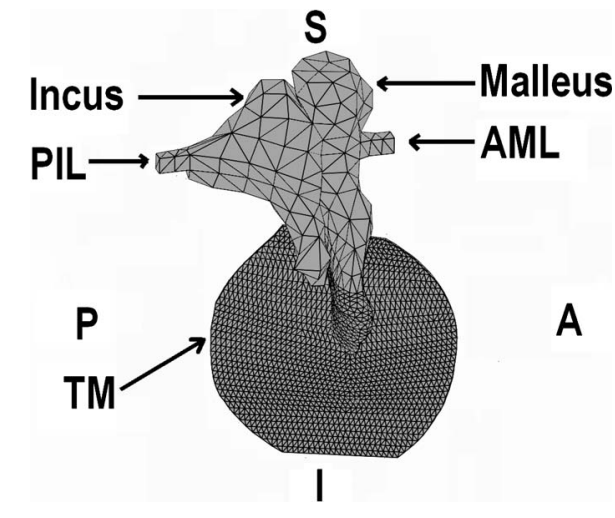

FIG. 1. Medial view of the middle-ear model. $\mathrm{S}$ is superior, I is inferior, $\mathrm{P}$ is posterior, $\mathrm{A}$ is anterior. AML is the anterior mallear ligament, PIL is the posterior incudal ligament.

newborn canal-wall displacement (Qi et al., 2006). Our results indicated that the volume changed by between 27 and $75 \%$ in response to static pressures of $\pm 3 \mathrm{kPa}$. The purpose of the present study is to extend our earlier work by including the middle ear, in order to investigate newborn TM volume displacements under tympanometric pressures.

In this study, we present a three-dimensional nonlinear finite-element model of a 22-day-old newborn middle ear. The geometry is based on a clinical $\mathrm{x}$-ray computed tomography (CT) scan and the published literature. A polynomial hyperelastic constitutive law is applied to model large deformations of the TM. Plausible ranges of material properties of the newborn middle ear are explored. The volume displacement of the TM under high static pressures is estimated in both open-cavity and closed-cavity conditions. The simulated TM volume displacement is compared with equivalentvolume differences calculated from measurements in both healthy full-term newborns (Margolis et al., 2003; Shahnaz et al., 2008) and neonatal intensive care unit (NICU) newborns (Margolis et al., 2003).

\section{MATERIALS AND METHODS}

\section{A. 3D reconstruction}

The geometry of the model is based on the same data as our ear-canal model (Qi et al., 2006), namely, a clinical CT scan of a 22-day-old newborn. The CT scan contained 47 horizontal slices. Two local programs, Fie and Tr3 (http:// audilab.bmed.mcgill.ca/sw/), were used to generate a surface model. A solid model with tetrahedral elements was then generated using Gmsh (http://www.geuz.org/gmsh/) and imported into COMSOL version 3.3 (http://www.comsol.com) for finite-element analysis. Figure 1 shows a medial view of the TM, ossicles, and ligaments.

The TM, malleus, incus, anterior mallear ligament, and posterior incudal ligament were modeled using second-order ten-node tetrahedral elements. Second-order tetrahedral elements can model complex structures more accurately with fewer elements. This leads to more accurate simulation results and saves computation time.

The pars flaccida is not included in this study for two reasons. First, the area of the pars flaccida is much smaller than that of the pars tensa (e.g., Anson and Donaldson,
1981). Second, even in the gerbil, with a much larger pars flaccida, the volume displacement of the TM is caused mainly by the deformation of the pars tensa when the static pressures are varied from 0.4 to $2 \mathrm{kPa}$. The volume displacements of the pars flaccida remain nearly unchanged for pressures above $0.4 \mathrm{kPa}$ (Dirckx et al., 1998).

Dirckx and Decraemer (2001) studied gerbil eardrum deformations under quasi-static pressures of $\pm 2 \mathrm{kPa}$. They found that the cochlea, tensor tympani, and stapes had little influence on eardrum deformations. Thus, in this model, we do not take into account the tensor tympani, the stapes, or the cochlear load.

There are two synovial joints linking the ossicles together. The incustapedial joint was not included here because the stapes was not included. Studies have shown that the incudomallear joint is somewhat flexible (e.g., Decraemer and Khanna, 1995; Nakajima et al. 2005) but it has for simplicity been assumed to be rigid in this study The effect on TM volume displacement is probably small.

\section{B. Material properties and hyperelastic models 1. Thickness of TM}

The thickness distribution of the human adult TM has been measured by several investigators (e.g., Lim, 1970; Schmidt and Hellstrom, 1991). It has been found that there is significant variation in the thickness across the surface of the TM and large intersubject differences. Recently, Kuypers et al. (2006) measured three human adult TM thicknesses using confocal microscopy. They found that the pars tensa has a rather constant thickness in a central region, ranging from 0.040 to $0.12 \mathrm{~mm}$ across three subjects. The study of newborn TM thickness is sparse. To the best of our knowledge, the only study was conducted by Ruah et al. (1991). They investigated the thickness distribution for different ages of human TMs using histological images with the help of both light and electron microscopy. They measured the thicknesses of TMs from 54 temporal bones, aged from newborn to adult. They found that from newborn to adult the thickness of the TM decreases significantly. Thicknesses of the pars tensa were measured in four different quadrants. They found in newborns that the thickness of the posterior-superior region ranged from 0.4 to $0.7 \mathrm{~mm}$; the thicknesses of the posterior-inferior, anterior-superior and anterior-inferior regions were similar, ranging from 0.1 to $0.25 \mathrm{~mm}$; and the thickness of the umbo area ranged from 0.7 to $1.5 \mathrm{~mm}$.

In this study, a nonuniform thickness for the TM model was developed based on the measurements of Ruah et al. (1991), supplemented by thickness measurements on histological images from two one-month-old ears. The thicknesses of the posterior-inferior, anterior-superior, and anterior-inferior quadrants are all $0.1 \mathrm{~mm}$ in our model. The thickness of the posterior-superior quadrant is $0.5 \mathrm{~mm}$. In the vicinity of the umbo the TM thickness (excluding the manubrium) is $0.75 \mathrm{~mm}$.

\section{Young's modulus of TM}

The TM consists of three layers: the epidermis, the outer layer, whose ultrastructure is similar to the epidermis of skin; 
the lamina propria, the middle layer, which contains loose ground matrix and two layers of densely packed collagen fibers arranged in radial and circular patterns, respectively; and the lamina mucosa, the thin inner layer, which contains a large number of columnar cells (Lim, 1970). The overall mechanical properties of the TM depend mainly on the lamina propria, which is characterized by the presence of type II collagen fibers.

The Young's modulus of the human adult TM has been investigated by both experimental and modeling studies. Békésy (1960) first measured Young's modulus of TM using a beam-bending test on a strip of cadaver TM. He reported a Young's modulus of $20 \mathrm{MPa}$. Kirikae (1960) measured the Young's modulus of a strip of TM using a longitudinal vibration. He reported a Young's modulus of about $40 \mathrm{MPa}$. Decraemer et al. (1980) used a quasi-static uniaxial tensile test on strips of TM. They found that the incremental Young's modulus was shown to vary with the stress level, from almost zero up to a value of approximately $23 \mathrm{MPa}$. Cheng et al. (2007) also used uniaxial tensile tests and combined the experimental results with an Ogden hyperelastic model. They estimated that the Y.m of the TM is between 0.4 and $22 \mathrm{MPa}$, again depending on the stress level. Fay et al. (2005) proposed three approaches to estimate the Young's modulus of the TM in adult human and cats. They concluded that the Young's modulus of the adult human TM is between 30 and $90 \mathrm{MPa}$ for an isotropic model and 100-400 MPa for an orthotropic TM model. Their values are much higher than those of other investigators at least in part because they are calculated based on the thicknesses of the dense fibrous layers of the TM rather than on the overall thickness.

To date, the Young's modulus of the newborn TM has not been investigated. Ruah et al. (1991) examined the ultrastructure of the TM from newborns to adults using electron microscopy. They observed that with age the TM becomes less vascular and less cellular, and has more collagen fibers and elastins. They concluded that age-related changes occurring in the lamina propria of the TM are very similar to changes observed in the human skin. Although no direct measurements of the mechanical properties of the TM in newborns are available, the age-related mechanical properties of various other collagenous tissues have been studied. The mechanical properties of collagen are mainly decided by its density, length, and cross-linking, and by the diameters and orientations of the collagen fibrils and fibers. The lengths of collagen fibers also increase with age. It has been reported that fibers in rat tail tendon increased from $20-100 \mathrm{~nm}$ at four weeks old to 30-200 nm by 1 year old (e.g., Schwarz, 1957). It has also been found that collagen density and crosslinks increase with age and that collagen becomes more aligned with age (e.g., Hall, 1976; Stoltz, 2006). Age-related Young's modulus changes of human skin have also been reported. Rollhauser (1950) studied the age-related Young's modulus of skin from 3-month-old infants to adults. He found that the Young's modulus of skin in adults is approximately 7-8 times as large as that in infants. Similar results were reported by Yamada (1970). They found that the Young's modulus of skin in adults is about six times as large as the Young's modulus of infant skin. Grahame and Holt
(1969) found that the Young's modulus of skin increased by a factor of 2 from 19 years old to 80 years old. Histological examination of the skin also shows that as the age of the skin increases the collagen density becomes higher and the collagen fibers become less extensible (Agache et al., 1980).

In this study, three Young's moduli are used for the TM: 0.6, 1.2 and 2.4 MPa. Consistent with the adult/infant ratios of 6 to 8 found by Rollhauser (1950) and Yamada (1970), the 0.6 MPa value is several times smaller than a typical smallstrain Young's modulus from Decraemer et al. (1980); and 2.4 MPa is approximately 8-10 times smaller than the measurement of Békésy (1960) and the large-strain value of Decraemer et al. (1980).

\section{Young's moduli of ossicles and ligaments}

Studies have shown that development of the ossicles continues after birth. Ossicular weight and size are smaller in newborns (Olszewski, 1990). It has been reported that a long, narrow anterior mallear process exists in at least some newborns (Anson and Donaldson, 1981; Unur et al., 2002). We observed a long process in our 1-month-old histological images. We do not see a long process in our 22-day-old newborn CT scan, probably due to the limited resolution of the scan.

Yokoyama et al. (1999) studied the postnatal development of the ossicles in 32 infants and children, aged from one day to nine years. They found that the newborn malleus and incus contain much bone marrow, which is gradually replaced by bone. They concluded that ossification of the ossicles takes place after birth until about 25 months.

In this study, the Young's modulus of the ossicles is assumed to be 1,3 , or $5 \mathrm{GPa}$. The value of $5 \mathrm{GPa}$ is at the low end of the range of the Young's modulus of bone given by Nigg and Herzog (1999), and it is approximately 2.5 times smaller than the values used in adult middle-ear models (e.g., Koike et al., 2002). Similarly, the Young's modulus of the ligaments is assumed to be 1,3 , or $5 \mathrm{MPa}$, which is approximately 2 to 10 times smaller than typical values used in human adult middle-ear models (e.g., Koike et al., 2002). Ligaments were assumed to be hyperelastic. Ossicles were assumed to have linear material properties due to the high Young's modulus.

\section{Hyperelastic model}

The method is only briefly described here, since a detailed report has been published elsewhere (Qi et al., 2006). A polynomial hyperelastic constitutive law was applied, which allows us to simulate nearly incompressible biological materials with large deformations. The strain energy is given by

$$
W=C_{10}\left(I_{1}-3\right)+C_{01}\left(I_{2}-3\right)+\frac{\kappa}{2}(J-1)^{2},
$$

where $I_{1}$ and $I_{2}$ are the first and second strain invariants; $J$ is the volume-change ratio; and $\kappa$ is the bulk modulus. $C_{10}$ and $C_{01}$ are material constants. Under small strains the Young's modulus of the material, $E$, may be written as 


$$
E=6\left(C_{10}+C_{01}\right)
$$

and the bulk modulus may be written as

$$
\kappa=\frac{3}{3(1-2 \nu)},
$$

where $\nu$ is Poisson's ratio. We assume that the Poisson's ratios of the TM and ligaments are 0.48 , which is a typical value used for nearly incompressible soft tissue (e.g., Qi et al., 2006); and that the Poisson's ratio of the ossicles is 0.3 , a widely used value for bone (e.g. Funnell and Laszlo, 1982). The ratio $C_{10}: C_{01}$ is taken to be $1: 1$, which has been widely used for biological soft tissue (e.g., Mendis et al., 1995; Samani and Plewes, 2004; Qi et al., 2006); from Eq. (2), therefore, $C_{10}=C_{01}=E / 12$.

The TM volume displacement was calculated by the integration of the nodal displacements over the entire TM surface using COMSOL.

\section{Boundary conditions}

The boundary of the TM and the ends of the anterior mallear and posterior incudal ligaments are taken to be fixed. The positive and negative static pressures are uniformly applied to the lateral surface of the TM.

\section{Middle-ear cavity}

The middle-ear cavity is an irregular, air-filled space within the temporal bone, and is mainly comprised of four parts: tympanic cavity, aditus ad antrum, mastoid antrum, and mastoid air cells (e.g. Anson and Donaldson, 1981). In the human adult, the middle-ear cavity volume is between 2000 and $22000 \mathrm{~mm}^{3}$ (e.g., Molvær et al., 1978). The air enclosed in the middle-ear cavity has a compliance that is proportional to its volume, so the larger the volume of the trapped air, the larger the compliance. Studies have shown that the middle-ear cavity may exert significant effects on middle-ear admittance (e.g., Zwislocki, 1962; Guinan and Peake, 1967; Funnell and Laszlo, 1982; Ravicz and Rosowski, 1997; Stepp and Voss, 2005). Ravicz et al. (1992), for example, estimated that reducing the air volume of the gerbil middle-ear cavity by $75 \%$ would approximately triple the effective middle-ear input impedance.

The compliance at the TM $\left(C_{\mathrm{TM}}\right)$ can be written as

$$
1 / C_{\mathrm{TM}}=1 / C_{\mathrm{TOC}}+1 / C_{\mathrm{CAV}},
$$

where $C_{\mathrm{TOC}}$ is the compliance of the TM, ossicles and cochlea; and $C_{\mathrm{CAV}}$ is the compliance of the middle-ear air cavity [cf. Stepp and Voss, 2005, Eq. (2)]. In our case $C_{\mathrm{TOC}}$ represents the compliance of the TM, malleus, and incus, since the stapes and cochlea are not included in our model. [Note that the compliances $C_{\mathrm{TM}}, C_{\mathrm{TOC}}$, and $C_{\mathrm{CAV}}$ are not related to the material constants $C_{10}$ and $C_{01}$ in Eq. (1)].

Previous studies have shown that the mastoid grows in all three dimensions, length, width, and depth, from birth to adulthood (Eby and Nadol, 1986). However, the volume of the mastoid in infants has not been quantitatively measured so far. To the best of our knowledge, only the tympanic cavity has been quantitatively measured in infants. Ikui et al.
(2000) reconstructed 14 normal human temporal bones aged from 3 months old to adulthood. They reported that the tympanic cavity is about 1.5 times as large in adults (about $640 \mathrm{~mm}^{3}$ ) as in infants (about $450 \mathrm{~mm}^{3}$ ).

One factor affecting the volume of the middle-ear cavity in newborns and infants is the presence of residual mesenchyme (embryonic tissue of mesodermal origin). It has been reported that most of the mesenchyme is found in the aditus ad antrum, the round-window niche and the oval-window niche (Takahara et al., 1986; Northrop et al., 1986). Northrop et al. (1986) found that the volume of mesenchyme remained constant at approximately $72 \mathrm{~mm}^{3}$ in newborns from 20 to 36 days old. They estimated that mesenchyme probably occupies less than one-tenth of the entire middle-ear cavity.

In this study, the middle-ear cavity volume was estimated based on our CT-scan reconstruction. The mesenchyme was excluded from the calculation. The tympanic cavity alone is approximately $330 \mathrm{~mm}^{3}$, which is smaller than the reports from Ikui et al. (2000). This is consistent with the fact that our subject was a 22-day-old while their subjects were about 3 months old. It is very difficult to accurately estimate the entire middle-ear cavity volume because the mastoid antrum and some air-cell spaces have very complicated shapes that are difficult to delineate accurately in the CT images. Based on an approximate segmentation of all but the smallest spaces, the combined volume of the aditus ad antrum, the mastoid antrum, and the mastoid air cells in our scan was estimated to be between 400 and $600 \mathrm{~mm}^{3}$. The total middle-ear cavity volume is thus between 730 and $930 \mathrm{~mm}^{3}$. For the model we have thus used minimum and maximum middle-ear cavity-volume parameter values of $700 \mathrm{~mm}^{3}$ and $1000 \mathrm{~mm}^{3}$, respectively.

\section{Tympanometry measurements}

The multifrequency tympanometry data for well babies presented here are based on measurements from Shahnaz et al. (2008). Sixteen full-term healthy 3-week-olds participated in the study. All infants passed a hearing screening at birth and again at 3 weeks of age. Multifrequency tympanometry was done in both ears of 15 out of 16 subjects, and in the right ear of the remaining subject. Tympanograms were recorded in the 31 ears using the Virtual 310 system with the extended high-frequency option. The admittance magnitude and phase were recorded at nine frequencies $(226$, $355,450,560,630,710,800,900$ and $1000 \mathrm{~Hz}$ ). The susceptance and conductance were derived from the measured magnitude and phase. The pump rate was $125 \mathrm{daPa} / \mathrm{s}$ and the pressure was varied from +250 to $-300 \mathrm{daPa}$ ( $1 \mathrm{daPa}$ $=10 \mathrm{~Pa}$ ). For a more detailed description see Shahnaz et al. (2008).

We use the following equations to calculate equivalent volumes (Shanks et al., 1993) from the susceptance tails [Eq. (5)] and from the admittance tails [Eq. (6)] respectively:

$$
V_{\mathrm{ea}}^{B \pm}=B^{ \pm} \frac{1000}{f / 226},
$$




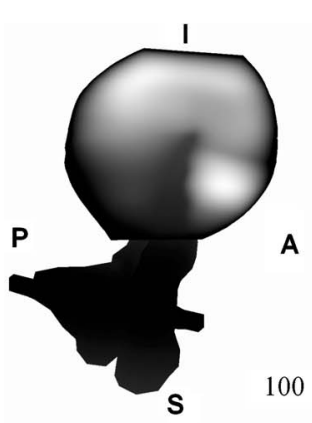

100
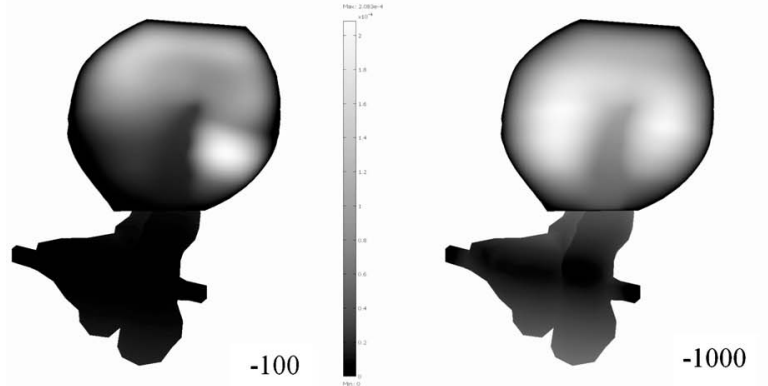

$$
V_{\mathrm{ea}}^{Y \pm}=Y^{ \pm} \frac{1000}{f / 226},
$$

where $V_{\text {ea }}^{B \pm}$ and $V_{\text {ea }}^{Y \pm}$ represent the equivalent volume $\left(\mathrm{mm}^{3}\right)$ calculated from the positive or negative susceptance or admittance tail; $B^{ \pm}$and $Y^{ \pm}$are the susceptance and the admittance magnitude at the positive $(+)$ or negative $(-)$ tail, respectively; and $f$ is frequency $(\mathrm{Hz})$. It should be noted that Eq. (6) is valid only when the conductance (the real part of the admittance) is zero. For newborns, the equivalent volume calculated from Eq. (6) may include significant errors due to nonzero conductance at the tails. In this study, however, the model results are compared with the difference between the equivalent volumes at the two tails $\left(\Delta V_{\mathrm{ea}}^{B}, \Delta V_{\mathrm{ea}}^{Y}\right)$, calculated as

$$
\begin{aligned}
& \Delta V_{\mathrm{ea}}^{B}=V_{\mathrm{ea}}^{B+}-V_{\mathrm{ea}}^{B-}, \\
& \Delta V_{\mathrm{ea}}^{Y}=V_{\mathrm{ea}}^{Y+}-V_{\mathrm{ea}}^{Y-} .
\end{aligned}
$$

As discussed in Sec. IV below, in newborns the conductances at the two tails are almost equal and therefore almost cancel each other.

\section{RESULTS}

\section{A. Model displacements}

Convergence tests were conducted to investigate how many elements should be used in the model. A nonuniform mesh was created. Four different resolutions were compared. The TM has nominal numbers of elements per diameter of $80,120,160$, and 200, respectively. The ossicles and ligaments have nominal numbers of elements per diameter of 20 , 40,60 , and 90, respectively. We found that the difference in TM volume displacement is less than $1.7 \%$ between the model with 160 elements/diameter for the TM and 40 elements/diameter for the ossicles and ligaments and the model with 200 elements/diameter for the TM and 90 elements/diameter for the ossicles and ligaments. Thus, the

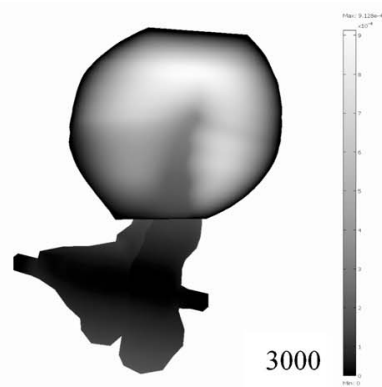

FIG. 2. Simulated displacement patterns for static pressures of \pm 100 , \pm 1000 and $\pm 3000 \mathrm{~Pa}$. Lighter colors represent larger values.

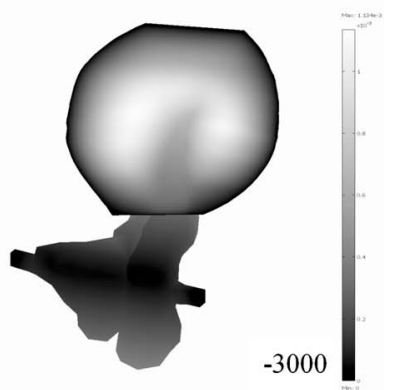

former model (160 and 40 elements/diameter) was selected for further simulations. The model has a total of 12815 elements, 9250 of which belong to the TM.

Our simulations show that varying the Young's modulus of the ossicles and ligaments has little effect on the TM volume displacements. The changes of the TM volume displacements are less than 3\% when the Young's modulus of the ossicles increases from 1 to $6 \mathrm{GPa}$. The changes of the TM volume displacements are less than 6\% when the Young's modulus of the ligaments increases from 0.6 to $6 \mathrm{MPa}$.

Figure 2 shows the model displacement patterns corresponding to different static pressures under open-cavity conditions. The location of the maximum displacement moves when the pressures are changed, which agrees with observations in human adult middle-ear measurements (Dirckx and Decraemer, 1991). At low pressures $( \pm 100 \mathrm{~Pa})$, the negative and positive displacement patterns are similar, with the maximum displacements in the antero-superior quadrant. When pressures are increased, the negative and positive displacement patterns become significantly different from each other. At the extreme positive pressure, the maximum displacement occurs inferiorly. At the extreme negative pressure, however, the maximum displacements occur anteriorly and posteriorly.

\section{B. Middle-ear cavity effects on TM volume displacement}

Our finite-element model does not explicitly include the middle-ear cavity. We use Boyle's Law to estimate the effects of the cavity volume on TM volume displacements. Details are given in the Appendix.

Figure 3 compares the model TM volume displacements corresponding to different Young's moduli of the TM under open and closed-cavity conditions $\left(700 \mathrm{~mm}^{3}\right)$, and the TM volume displacement measured in adults (Elner et al., 1971; Dirckx and Decraemer, 1991). The TM volume-displacement curves are nonlinear, with larger slopes for low pressures than for high pressures; and asymmetrical, with larger dis- 


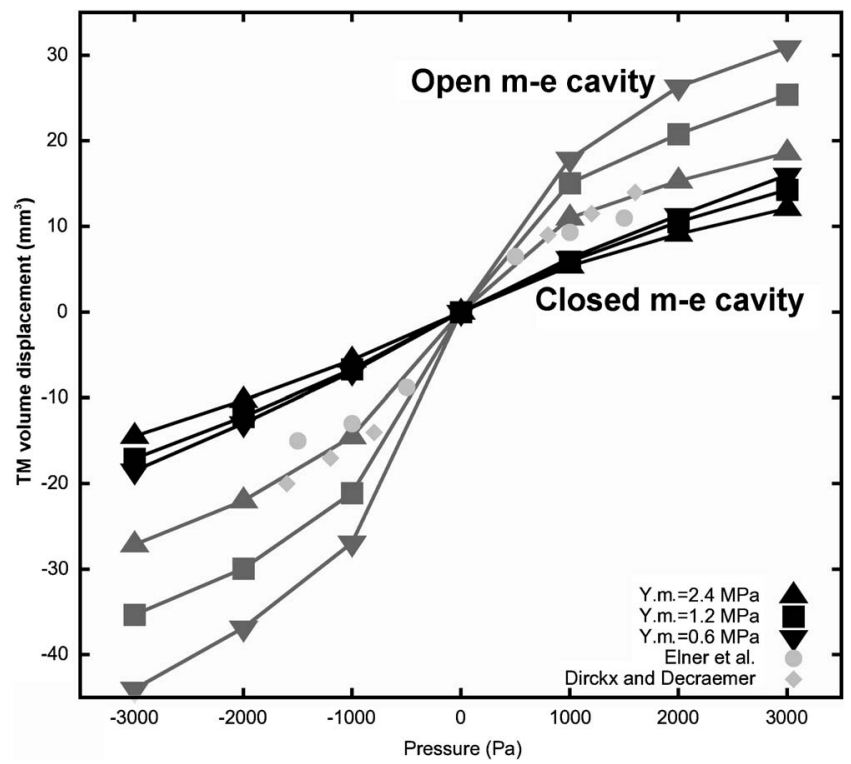

FIG. 3. Simulated TM volume displacements as functions of pressure, for different TM Young's moduli, for both open middle-ear cavity and closed middle-ear cavity $\left(700 \mathrm{~mm}^{3}\right)$, and experimental volume displacements measured in human adults from Dirckx and Decraemer (1992), Table VI and Elner et al. (1971), Table III, respectively. Dirckx and Decraemer (1992) gave middle-ear cavity pressures rather than canal pressures, so their curve has been reversed.

placements for negative pressures, which agrees with adult TM measurements (Dirckx and Decraemer, 1991; Elner et al., 1971). The form of the observed nonlinearity is determined by a combination of the material nonlinearity [expressed by Eq. (1)] and geometric nonlinearities resulting from the large deformations.

Our simulation results indicate that, from -3 to $+3 \mathrm{kPa}$, the TM volume displacements are approximately 27,32 , and $35 \mathrm{~mm}^{3}$ when the middle-ear cavity volume is $700 \mathrm{~mm}^{3}$; and approximately 46,60 , and $75 \mathrm{~mm}^{3}$ under open-cavity conditions, corresponding to Young's moduli of the TM of 2.4, 1.2 , and $0.6 \mathrm{MPa}$. The closed middle-ear cavity significantly reduces the TM volume displacements, and also reduces the degree of non1inearity and asymmetry of the TM volume displacement. The TM volume displacements under opencavity conditions are about 1.7-2.2 times as large as those under closed-cavity conditions with a volume of $700 \mathrm{~mm}^{3}$. The simulated TM volume displacements under open-cavity conditions show an asymmetry similar to that of the volume displacements measured in adults, with larger volume displacements at negative pressures.

Figure 4 compares the TM volume displacements between -3 and $+3 \mathrm{kPa}$ when the middle-ear cavity is $700 \mathrm{~mm}^{3}, 1000 \mathrm{~mm}^{3}$, and open. When the middle-ear cavity volume increases, the TM volume displacement increases, and the nonlinearity and asymmetry of the TM volume displacement increase as well. When the cavity volume increases from 700 to $1000 \mathrm{~mm}^{3}$ (an increase of about 43\%), the TM volume displacements increase by approximately $16 \%, 20 \%$, and $22 \%$ for TM Young's moduli of $2.4,1.2$, and $0.6 \mathrm{MPa}$, respectively. When the cavity volume increases from $1000 \mathrm{~mm}^{3}$ to the open situation (infinitely large), the

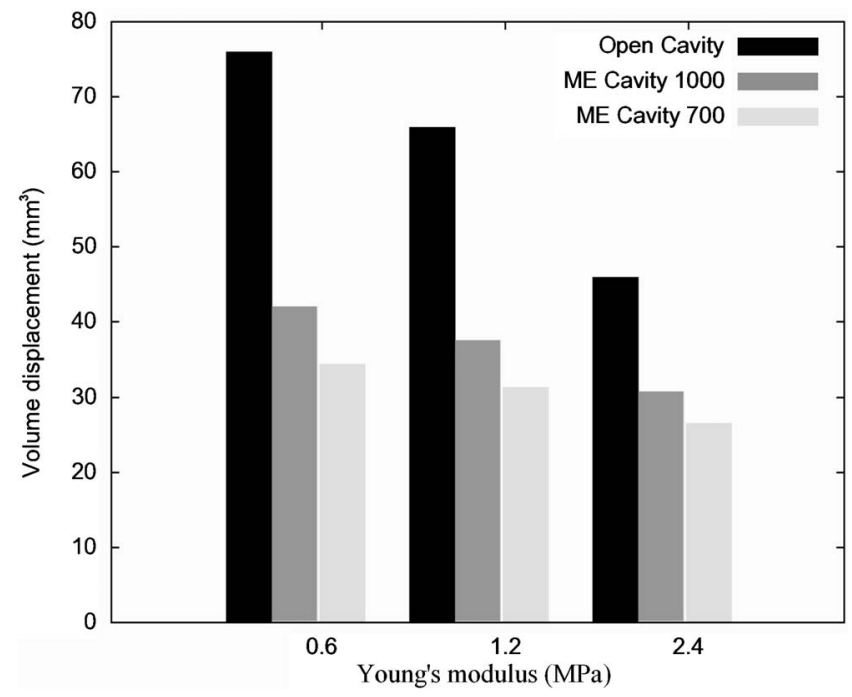

FIG. 4. Simulated TM volume displacements between -3 and $+3 \mathrm{kPa}$, for different middle-ear cavity volumes $\left(700,1000 \mathrm{~mm}^{3}\right.$ and open cavity).

TM volume displacements increase by $50 \%, 81 \%$, and $88 \%$ for TM Young's moduli of 2.4, 1.2, and $0.6 \mathrm{MPa}$, respectively.

\section{Comparisons with tympanometric data}

To date, no direct measurements of newborn TM displacements have been made. Thus, in this section we shall compare our simulation results with two sets of tympanometric equivalent-volume differences, one calculated from 3-week-olds (Shahnaz et al., 2008) and the other calculated from healthy infants and NICU infants aged from 1 day to 2 months old (Margolis et al., 2003).

\section{Equivalent-volume differences from Shahnaz et al.}

The equivalent-volume difference $\left(\Delta V_{\mathrm{ea}}^{\mathrm{B}}\right)$ between the positive tail $(+2.5 \mathrm{kPa})$ and the negative tail $(-2.75 \mathrm{kPa})$ was derived from susceptances using Eq. (7) in 163 -week-olds (Shahnaz et al., 2008). Figure 5 shows the $\Delta V_{\mathrm{ea}}^{\mathrm{B}}$ (median and 25th and 75th percentiles) for left and right ears combined. As shown in the figure, the medians of $\Delta V_{\mathrm{ea}}^{\mathrm{B}}$ in newborns

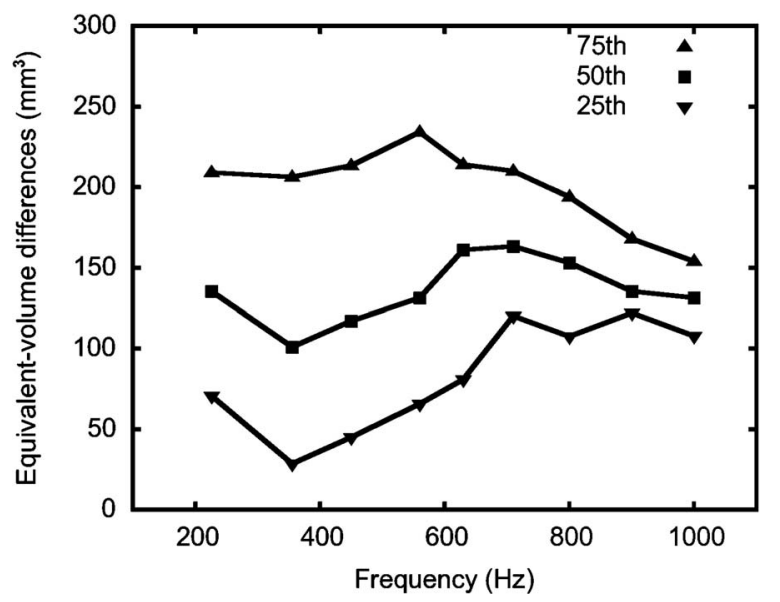

FIG. 5. Equivalent-volume differences (median and 25th and 75th percentiles) between susceptance tails from study of Shahnaz et al. (2008). 
stay almost constant over the entire frequency range. The median $\Delta V_{\text {ea }}^{\mathrm{B}}$ across frequencies is about $132 \mathrm{~mm}^{3}$.

Our simulation results indicate that from -2.75 to $+2.5 \mathrm{kPa}$ the TM volume displacements, corresponding to a Young's modulus of the TM of $2.4,1.2$ or $0.6 \mathrm{MPa}$, were approximately 24,28 , and $31 \mathrm{~mm}^{3}$ for a middle-ear cavity volume of $700 \mathrm{~mm}^{3}$, and 28,34 , and $38 \mathrm{~mm}^{3}$ for a cavity volume of $1000 \mathrm{~mm}^{3}$.

\section{Equivalent-volume differences from Margolis et al.}

Margolis et al. (2003) investigated the $1 \mathrm{kHz}$ admittance both in 46 ears of 30 full-term healthy newborns (aged 2-4 weeks) and in 105 ears of 65 NICU newborns (aged 3.9 \pm 3.8 weeks, mean $\pm \mathrm{SD})$. The equivalent-volume difference $\left(\Delta V_{\mathrm{ea}}^{\mathrm{Y}}\right)$ between the positive tail $(+2 \mathrm{kPa})$ and the negative tail $(-4 \mathrm{kPa})$ was derived from the admittance using Eq. (8). The median $\Delta V_{\mathrm{ea}}^{\mathrm{Y}}$ at $1000 \mathrm{~Hz}$ is 158 and $136 \mathrm{~mm}^{3}$ for NICU newborns and healthy full-term newborns, respectively.

Our simulation results indicate that from -4 to $+2 \mathrm{kPa}$ the TM volume displacements, corresponding to a Young's modulus of the TM of $2.4,1.2$ or $0.6 \mathrm{MPa}$, were approximately 28,33 , and $36 \mathrm{~mm}^{3}$ for a middle-ear cavity volume of $700 \mathrm{~mm}^{3}$, and 33,39 , and $44 \mathrm{~mm}^{3}$ for a cavity volume of $1000 \mathrm{~mm}^{3}$.

The predicted TM volume displacements calculated for the NICU newborns are larger than those calculated for the healthy newborns. This may be caused by the age difference between the two groups. The healthy-newborn ages were from 2 to 4 weeks, while the NICU-newborn age distribution was $3.9 \pm 3.8$ weeks (mean $\pm \mathrm{SD}$ ). A larger number of very young infants in the NICU group might account for the larger median $\Delta V_{\text {ea }}$ in that group.

\section{Comparison}

In both cases the simulation results are lower than the median equivalent-volume differences calculated from tympanometric measurements. This is consistent with the fact that the experimental equivalent-volume changes include contributions from the movements of the ear-canal wall, probe tip, and tympanic ring as well as the TM. This will be further discussed below.

\section{DISCUSSION AND CONCLUSIONS}

A nonlinear hyperelastic model of the newborn middle ear is presented and compared with tympanometric data. For static pressures from $-3 \mathrm{kPa}$ to $+3 \mathrm{kPa}$, the simulated $\mathrm{TM}$ displacements and volume displacements are nonlinear.

In our simulations, the TM volume displacements show considerable asymmetry under open-cavity conditions, with larger displacements for negative pressures. Adult human TM volume displacements also displayed asymmetry in the measurements of Dirckx and Decraemer (1992), which were conducted under open-cavity conditions, and in the measurements of Elner et al. (1971), which were conducted under closed-cavity conditions. The similarity between the measurements of Dirckx and Decraemer and those of Elner et al. suggests that in adults the middle-ear cavity volume generally has little effect on the TM volume displacement. This does not appear to be true for newborns.

Our simulated TM volume displacements are nearly symmetrical under closed-cavity conditions, as shown in Fig. 3 . The reason for the near symmetry under closed-cavity conditions is that the newborn cavity is relatively small, so $C_{\mathrm{CAV}}$ is relatively low, which leads to smaller displacements. This means that the TM is not driven into its nonlinear range. This is similar to the way that the nonlinearities decrease when Young's modulus increases: The system is still intrinsically nonlinear but it is not pushed so far into the nonlinear range.

The effects of cavity volume on TM volume displacements increase as the Young's modulus of the TM decreases. As shown in Fig. 4, when the volume of the middle-ear cavity increases from 700 to $1000 \mathrm{~mm}^{3}$, the TM volume displacements increase by $16 \%, 20 \%$, and $22 \%$ when the Young's modulus of the TM is $2.4,1.2$, and $0.6 \mathrm{MPa}$, respectively. Similarly, when the volume of the middle-ear cavity increases from $700 \mathrm{~mm}^{3}$ to infinitely large (the open-cavity condition), the TM volume displacements increase by $70 \%$, $91 \%$, and $117 \%$ when the Young's modulus of the TM is 2.4 , 1.2 , and $0.6 \mathrm{MPa}$, respectively. This is to be expected because when the Young's modulus of the TM decreases, $1 / C_{\mathrm{TOC}}$ decreases and the ratio of $1 / C_{\mathrm{CAV}}$ to $1 / C_{\mathrm{TOC}}$ increases.

Our simulations show that the Young's modulus of the TM has a significant effect on the TM volume displacement, as shown in Figs. 3-5. The effect is more pronounced for a larger middle-ear cavity. As the Young's modulus of the TM decreases from 2.4 to $1.2 \mathrm{MPa}$ and then to $0.6 \mathrm{MPa}$, the TM volume displacements increase by approximately $19 \%$ and $10 \%$ when the middle-ear cavity is $700 \mathrm{~mm}^{3}$; by approximately $23 \%$ and $12 \%$ when the middle-ear cavity is $1000 \mathrm{~mm}^{3}$; and by approximately $44 \%$ and $15 \%$ when the middle-ear cavity is open.

The simulated TM volume changes do not reach a plateau when the pressure is varied to either $-3 \mathrm{kPa}$ or $+3 \mathrm{kPa}$, which is consistent with the nonflat tails often found in susceptance tympanograms in newborns (e.g., Paradise et al., 1976; Holte et al., 1990). The failure of the model to reach a plateau is also consistent with the report by Shanks and Lilly (1981) that even at pressures of +2 and $-4 \mathrm{kPa}$ the adult middle ear is not rigid.

The tail-to-tail equivalent-volume differences shown in Fig. 5 consist of two components: (1) the actual air-volume change in response to the static pressure, corresponding to the static displacement of the ear-canal wall, the TM and the probe tip; and (2) a component due to the vibration of the canal wall and TM in response to the probe tone. The actual air-volume change should be independent of frequency, while the vibration-related component is presumably dependent on frequency. Both our previous newborn ear-canal model (Qi et al., 2006) and the current middle-ear model under closed-cavity conditions predict nearly symmetrical nonlinear responses, which suggests that the vibrations at the extreme positive and negative pressures are similar. In that case, their effects will tend to cancel when subtracting either 

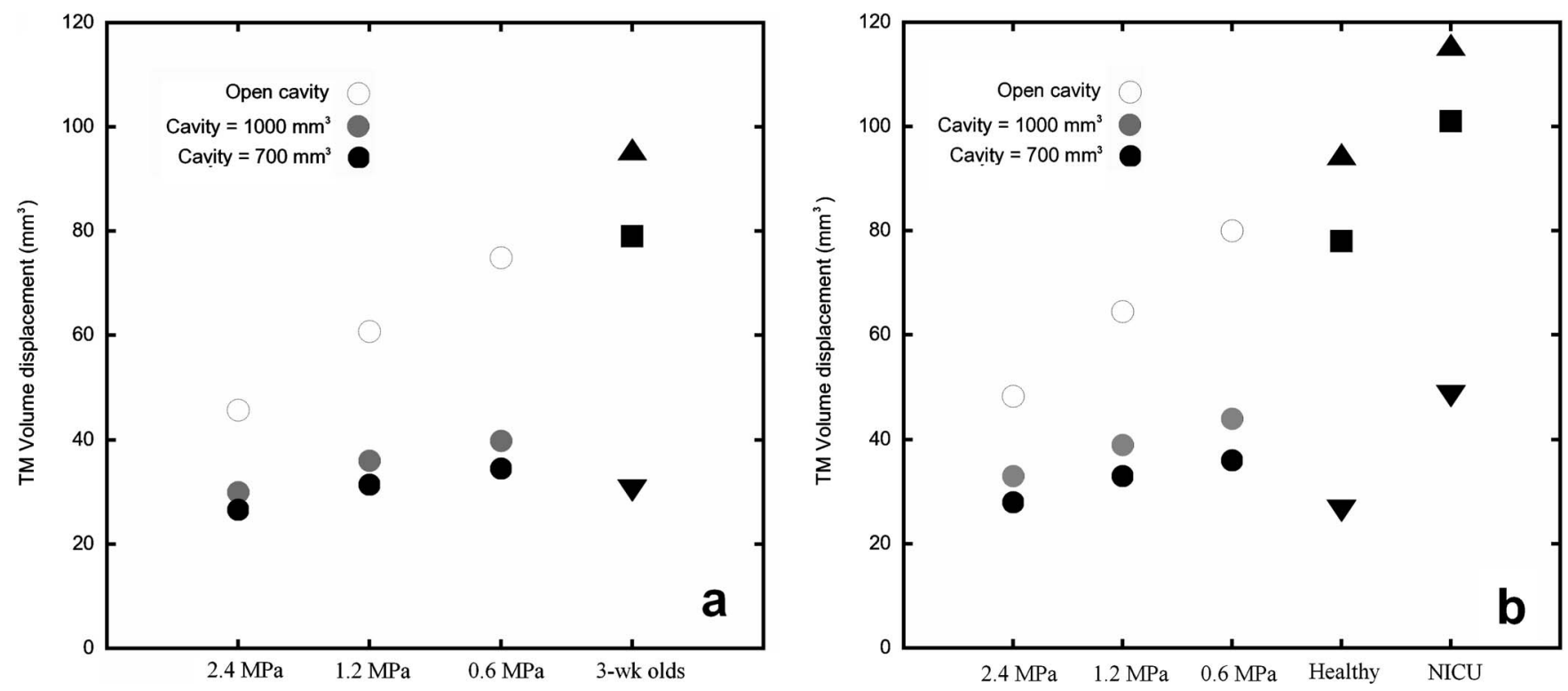

FIG. 6. Comparison of simulated TM volume displacements, for different cavity volumes, with the equivalent-volume differences in 3-week-old newborns (a), and with the equivalent-volume differences in NICU and healthy newborns (b).

admittances or susceptances and the $\Delta V_{\text {ea }}$ will be mainly determined by the actual volume change (Qi et al., 2006). In our analysis of the data of Shahnaz et al. (2008), shown in Fig. 5, the median $\Delta V_{\text {ea }}$ varies little across the entire frequency range, which is consistent with interpreting the equivalent-volume difference as the actual volume change. (It should be mentioned, however, that tail-to-tail equivalentvolume differences calculated for human adults may have a significant vibration-related component, given the asymmetrical TM volume displacement in adults.)

Based on our previous ear-canal model (Qi et al., 2006), when the Young's modulus of the ear-canal wall is 30, 60, and $90 \mathrm{kPa}$, the simulated canal-wall volume displacement is 101,53 , and $37 \mathrm{~mm}^{3}$, respectively, from -2.75 to $+2.5 \mathrm{kPa}$. Subtracting these canal-wall volume displacements from the median equivalent-volume change of $132 \mathrm{~mm}^{3}$ obtained from the tympanometric data of Shahnaz et al. (Sec. III C 1) yields predicted TM volume displacements of about 31, 79, and $95 \mathrm{~mm}^{3}$, respectively.

For use with the data of Margolis et al. (2003), the pressure response of our canal model has been extended from -3 to $-4 \mathrm{kPa}$. The resulting simulated canal-wall volume displacements, for Young's moduli of 30,60 , and $90 \mathrm{kPa}$, are 109, 56, and $42 \mathrm{~mm}^{3}$, respectively. Again subtracting the simulated canal-wall volume displacements from the median tympanometric equivalent-volume differences (Sec. III C 2), we obtain predicted TM volume displacements of 48, 101, and $115 \mathrm{~mm}^{3}$ for NICU newborns and 27, 77, and $94 \mathrm{~mm}^{3}$ for healthy full-term babies.

In Fig. 6, parts $a$ and $b$ compare the TM-model volume displacements under closed-cavity $\left(700\right.$ and $\left.1000 \mathrm{~mm}^{3}\right)$ and open-cavity conditions with the TM volume displacements predicted by combining our canal-model results with the measurements of Shahnaz et al. (2008) and Margolis et al. (2003), respectively.

In an attempt to obtain an estimate of canal-wall displacement separate from that of the TM, we note that Marg- olis et al. (2003) recommended using the peak-to-negativetail difference of admittance at the 5th percentile as a passfail criterion for conductive hearing loss. Since middle-ear effusion (MEE) is the most common cause of conductive hearing loss in newborns, we suppose that the pass-fail criterion can be used as a criterion for MEE. For newborns with MEE, the TM cannot move as freely as usual and the admittance of the middle ear may be nearly zero. As a result, the equivalent-volume difference $\left(\Delta V_{\mathrm{ea}}\right)$ between the two tails would be mainly due to the canal-wall, tympanic-ring and probe-tip movement. The $\Delta V_{\text {ea }}$ at the 5th percentile of Margolis et al. is $113 \mathrm{~mm}^{3}$. This is close to the maximum canalwall volume displacement of $109 \mathrm{~mm}^{3}$ predicted by our canal model, when the Young's modulus of the ear-canal wall is $30 \mathrm{MPa}$. In that case, the closed-cavity TM-model volume displacements are close to the minimum TM volume displacements predicted from the canal model. Note that the TM volume displacement predicted from our canal model actually also includes any volume displacements due to tympanic-ring and probe-tip movement. Thus, on the one hand, if we adopt the lowest Young's modulus (30 MPa) for the canal-wall model then the predicted canal-wall and TM volume displacements match the total volume displacements obtained from the tympanometric data. On the other hand, if the canal wall is stiffer, then we would predict some additional volume displacement due to the tympanic ring and probe tip. The fact that $113 \mathrm{~mm}^{3}$ is a large fraction of their median $\Delta V_{\text {ea }}^{\mathrm{Y}}$ values of $136 \mathrm{~mm}^{3}$ and $158 \mathrm{~mm}^{3}$ is consistent

TABLE I. Three sets of answers for initial cavity volume $=700 \mathrm{~mm}^{3}$ and canal pressure $=1 \mathrm{kPa}$.

\begin{tabular}{lcccc}
\hline \hline & $V_{1}$ & $P_{1}$ & $\Delta P$ & $\Delta V$ \\
\hline Answer 1 & 720.554 & 97147.5 & 3852.52 & 20.5539 \\
Answer 2 & 15.7314 & 0.444972 & $0.455072 \mathrm{E} 7$ & 715.731 \\
Answer 3 & 694.647 & 100771.0 & 229.475 & 5.35243 \\
\hline \hline
\end{tabular}




\begin{tabular}{|c|c|c|c|c|c|c|}
\hline \multirow{2}{*}{$\begin{array}{c}\text { Young's } \\
\text { modulus (MPa) }\end{array}$} & \multicolumn{6}{|c|}{ Pressure $(\mathrm{Pa})$} \\
\hline & -3000 & -2000 & -1000 & 1000 & 2000 & 3000 \\
\hline 2.4 & -14.44 & -10.26 & -5.55 & 5.35 & 9.07 & 12.09 \\
\hline 1.2 & -17.04 & -12.16 & -6.61 & 5.93 & 10.46 & 14.26 \\
\hline 0.6 & -18.86 & -12.97 & -6.90 & 6.23 & 11.26 & 15.60 \\
\hline
\end{tabular}

with our model-based prediction that the canal-wall volume displacement makes a major contribution to the total canal volume change. The relative contributions of these different components clearly depend strongly on the corresponding material properties, especially stiffnesses and TM thicknesses. Further work is required in order to further constrain estimates of the Young's moduli, and the effects of current simplifications such as the rigidity of the incudomallear joint and the uniform TM thickness in each quadrant should be explored.

As a first step in modeling the newborn middle ear, our results show that the volume of the middle-ear cavity and the Young's modulus of the TM have significant effects on the TM volume displacement. It is not clear whether the volume displacement of the probe tip and tympanic ring make significant contributions to the total volume change. It will be necessary to combine the ear-canal and middle-ear models and to incorporate the tympanic ring and the probe tip. Modeling the small-amplitude dynamic response of the ear canal and middle ear to the probe tone, and then combining that with the nonlinear static response modeled here, will permit a complete model of tympanometry in newborns.

\section{ACKNOWLEDGMENTS}

This work was supported by the Canadian Institutes of Health Research and the Natural Sciences and Engineering Research Council (Canada), the Fonds de recherche en santé du Québec, the Montréal Children's Hospital Research Institute, the McGill University Health Centre Research Institute, and the Hearing Foundation of Canada. The authors thank C. Northrop (Temporal Bone Foundation, Boston) for the histological images used to supplement and help interpret our CT scan, C. B. Ruah for helpful discussion of his TM thickness data, and J. Lufty for his work on the initial segmentation of the CT scan.

\section{APPENDIX: CALCULATION OF EFFECTS OF MIDDLE- EAR CAVITY ON TM VOLUME DISPLACEMENT}

Our finite-element model does not include the effects of the middle-ear cavity. In order to estimate the effects of the cavity on TM volume displacement, we start with Boyle's law, assuming that temperature is constant because the pressure changes are slow (cf. Elner et al., 1971):

$$
P_{0} V_{0}=P_{1} V_{1}
$$

where $P_{0}$ (in $\mathrm{Pa}$ ) is the initial pressure in the middle ear (atmospheric pressure, $10^{5} \mathrm{~Pa}$ ); $V_{0}\left(\right.$ in $\mathrm{mm}^{3}$ ) is the initial middle-ear cavity volume, before the TM is displaced; and $P_{1}$ and $V_{1}$ are the final pressure and volume in the middle ear. Suppose that overpressure $p$ is applied in the ear canal. The pressure difference across the TM is then

$$
\Delta P=P_{0}+p-P_{1}
$$

and the TM volume displacement is

$$
\Delta V=V_{0}-V_{1} \text {. }
$$

The relationship between $\Delta P$ and $\Delta V$ is defined by our finite-element model, as shown in Fig. 3. The relationship is strongly asymmetrical, but on each side of the origin it can be approximated by using a second-order polynomial equation. Therefore, for the purpose of calculating the effect of the closed middle-ear cavity, we represent the relationship by

$$
\Delta P=a \Delta V^{2}+b \Delta V,
$$

where $a$ and $b$ are fitted coefficients. The coefficients $a$ and $b$ in Eq. (A4) were estimated using the least-squares method (Gnuplot version 4.0, http://www.gnuplot.info). The coefficients were estimated separately for the positive-pressure and negative-pressure parts and for each of the three TM Young's modulus values. Therefore, six sets of $a$ and $b$ were estimated.

Given $P_{0}, V_{0}, p, a$ and $b$, we have four simultaneous equations (A1)-(A4) and four unknowns $\left(P_{1}, V_{1}, \Delta P\right.$ and

TABLE III. TM volume displacements for initial cavity volume $=1000 \mathrm{~mm}^{3}$.

\begin{tabular}{ccccccr}
\hline \hline & \multicolumn{5}{c}{ Pressure (Pa) } \\
\cline { 2 - 7 } $\begin{array}{c}\text { Young's } \\
\text { modulus (MPa) }\end{array}$ & -3000 & -2000 & -1000 & 1000 & 2000 & 3000 \\
\hline 2.4 & -17.14 & -12.49 & -7.01 & 6.50 & 10.53 & 13.72 \\
1.2 & -20.81 & -15.31 & -8.74 & 7.52 & 12.65 & 16.81 \\
0.6 & -23.40 & -16.82 & -9.37 & 8.11 & 14.02 & 18.90 \\
\hline \hline
\end{tabular}


$\Delta V$ ). The computer-algebra system Axiom (http://axiomwiki.newsynthesis.org) is used to solve the system of equations either symbolically or numerically.

If we adopt some specific values for the given parameters, e.g., $P_{0}=10^{5}, V_{0}=700, p=1000, a=8.89$, and $b=-4.7$, then we can solve the set of Eqs. (A1)-(A4) numerically using the Axiom solve command. Since the solution to the set of equations involves a cubic equation, we obtain three sets of answers, as shown in Table I. Since we know that $\Delta V>0$ and $\Delta V<V_{0}$, only one answer is physically reasonable. Thus we see that, for these particular values for $P_{0}, V_{0}$, $a$ and $b$, the TM volume displacement is approximately $5.35 \mathrm{~mm}^{3}$ when the canal pressure $p$ is $1 \mathrm{kPa}$.

The results for two different initial middle-ear volumes (700 and $1000 \mathrm{~mm}^{3}$ ) are given in Tables II and III for six different pressures $( \pm 1000, \pm 2000$ and $\pm 3000 \mathrm{~Pa})$ and three different values of TM Young's modulus $(0.6,1.2$ and $2.4 \mathrm{MPa}$ ). Only the physically reasonable solutions are shown in Tables II and III.

Agache, P. G., Monneur, C., Leveque, J. L., and De Rigal, J. (1980). "Mechanical properties and Young's modulus of human skin in vivo," Arch. Dermatol. Res. 269, 221-232.

Anson, B. J., and Donaldson, J. A. (1981). "The temporal bone," in Surgical Anatomy of the Temporal Bone, edited by B. J. Anson and J. A. Donaldson (Saunders, Philadelphia)

Békésy, G. V. (1960). Experiments in Hearing (AIP Press, New York).

Cheng, T., Dai, C., and Gan, R. Z. (2007). "Viscoelastic properties of human tympanic membrane," Ann. Biomed. Eng. 35, 305-314.

Decraemer, W. F., and Khanna, S. M. (1995). "Malleus vibration modeled as rigid body motion," Acta Otorhinolaryngol. Belg. 49, 139-145.

Decraemer, W. F., Maes, M. A., and Vanhuyse, V. J. (1980). "An elastic stress-strain relation for soft biological tissues based on a structural model," J. Biomech. 13, 463-468.

Dirckx, J. J. J., Buytaert, J. A. N., and Decraemer, W. F. (2006). "Quasistatic transfer function of the rabbit middle ear measured with a heterodyne interferometer with high-resolution position decoder," J. Assoc. Res. Otolaryngol. 7, 339-551.

Dirckx, J. J. J., and Decraemer, W. F. (1991). "Human tympanic membrane deformation under static pressure," Hear. Res. 51, 93-106.

Dirckx, J. J. J., and Decraemer, W. F. (1992). "Area change and volume displacement of the human tympanic membrane under static pressure," Hear. Res. 62, 99-104.

Dirckx, J. J. J., Decraemer, W. F., von Unge, M., and Larsson, C. (1997) "Measurement and modeling of boundary shape and surface deformation of the Mongolian gerbil pars flaccida," Hear. Res. 111, 153-164.

Dirckx, J. J. J., Decraemer, W. F., von Unge, M., and Larsson, C. (1998). "Volume displacement of the gerbil eardrum pars flaccida as a function of middle ear pressure," Hear. Res. 118, 35-46.

Dirckx, J. J. J., and Decraemer, W. F. (2001). "Effect of middle ear components on eardrum quasistatic deformation," Hear. Res. 157, 124-137.

Eby, T. L., and Nadol, J. B., Jr. (1986). "Postnatal growth of the human temporal bone. Implications for cochlear implants in children," Ann. Otol. Rhinol. Laryngol. 95, 356-364.

Elner, A., Ingelstedt, S., and Ivarson, A. (1971). "The elastic properties of the tympanic membrane system," Acta Oto-Laryngol. 72, 397-403.

Fay, J. Puria, S., Decraemer, W. F., and Steele, C. (2005). "Three approaches for estimating the elastic modulus of the tympanic membrane," J. Biomech. 38, 1807-1815.

Funnell, W. R. J., and Laszlo, C. A. (1982). "A critical review of experimental observations on eardrum structure and function," ORL 44, 181205.

Gaihede, M. (1999). "Mechanics of the middle ear system: Computerized measurements of its pressure-volume relationship," Auris Nasus Larynx 26, 383-399.

Grahame, R., and Holt, P. J. (1969). "The influence of ageing on the in vivo elasticity of human skin," Gerontologia 15, 121-319.

Guinan, J. J., Jr. and Peake, W. T. (1967). "Middle-ear characteristics of anesthetized cats," J. Acoust. Soc. Am. 41, 1237-1261.
Hall, D. A. (1976). The Aging of Connective Tissue (Academic, London). Holte, L., Cavanaugh, R. M., Jr., and Margolis, R. H. (1990). "Ear canal wall mobility and tympanometric shape in young infants," J. Pediatr. (St. Louis) 117, 77-80.

Ikui, A., Sando, I., Haginomori, S., and Sudo, M. (2000). "Postnatal development of the tympanic cavity: A computer-aided reconstruction and measurement study," Acta Oto-Laryngol. 120, 375-379.

Keefe, D. H., Bulen, J. C., Arehart, K. H., and Burns, E. M. (1993). "Earcanal impedance and reflectance coefficient in human infants and adults," J. Acoust. Soc. Am. 94, 2617-2637.

Keefe, D. H., and Levi, E. (1996). "Maturation of the middle and external ears: Acoustic power-based responses and reflectance tympanometry," Ear Hear. 17, 361-372.

Keefe, D. H., and Simmons, J. L. (2003). "Energy transmittance predicts conductive hearing loss in older children and adults," J. Acoust. Soc. Am. 114, 3217-3238.

Kirikae, I. (1960). The Structure and Function of the Middle Ear (University of Tokyo, Tokyo).

Koike, T., Wada, H., and Kobayashi, T. (2002). "Modeling of the human middle ear using the finite-element method," J. Acoust. Soc. Am. 111, 1306-1317.

Kuypers, L. C., Decraemer, W. F., and Dirckx, J. J. J. (2006). "Thickness distribution of fresh and preserved human eardrums measured with confocal microscopy," Otol. Neurotol. 27, 256-264.

Ladak, H. M., Decraemer, W. F., Dirckx, J. J. J., and Funnell, W. R. J. (2004). "Response of the cat eardrum to static pressures: Mobile versus immobile malleus," J. Acoust. Soc. Am. 116, 3008-3021.

Ladak, H. M., Funnell, W. R. J., Decraemer, W. F., and Dirckx, J. J. J. (2006). "A geometrically nonlinear finite-element model of the cat eardrum," J. Acoust. Soc. Am. 119, 2859-2868.

Larsson, C., Dirckx, J. J. J., Bagger-Sjöbäck, D., and von Unge, M. (2005). "Pars flaccida displacement pattern in otitis media with effusion in the gerbil," Otol. Neurotol. 26, 337-343.

Larsson, C., von Unge, M., Dirckx, J. J. J., Decraemer, W. F., and BaggerSjöbäck, D. (2001). "Displacement pattern of the normal pars flaccida in the gerbil," Otol. Neurotol. 22, 558-566.

Lee, C. Y., and Rosowski, J. J. (2001). "Effects of middle-ear static pressure on pars tensa and pars flaccida of gerbil ears," Hear. Res. 153, 146-163.

Lim, D. J. (1970). "Human tympanic membrane. An ultrastructural observation," Acta Oto-Laryngol. 70, 176-186.

Margolis, R. H., Bass-Ringdahl, S., Hanks, W. D., Holte, L., and Zapala, D. A. (2003). "Tympanometry in newborn infants $-1 \mathrm{kHz}$ norms," J. Am. Acad. Audiol 14, 383-392.

Margolis, R. H., Paul, S., Saly, G. L., Schachern, P. A., and Keefe, D. H. (2001). "Wideband reflectance tympanometry in chinchillas and human," J. Acoust. Soc. Am. 110, 1453-1464.

Margolis, R. H., and Shanks, J. E. (1991). "Tympanometry: Principles and procedures," in Hearing Assessment, edited by W. F. Rintelmann (Pro-Ed., Austin, Texas), pp. 179-246.

Mendis, K. K., Stalnaker, R. L., and Advani, S. H. (1995). "A constitutive relationship for large deformation finite element modeling of brain tissue," J. Biomech. Eng. 117, 279-285.

Meyer, S. E., Jardine, C. A., and Deverson, W. (1997). "Developmental changes in tympanometry: A case study," Br. J. Audiol. 31, 189-195.

Molvær, O., Vallersnes, F., and Kringlebotn, M. (1978). "The size of the middle ear and the mastoid air cell," Acta Oto-Laryngol. 85, 24-32.

Nakajima, H. H., Ravicz, M. E., Merchant, S. N., Peake, W. T., and Rosowski, J. J. (2005). "Experimental ossicular fixations and the middle ear's response to sound: Evidence for a flexible ossicular chain," Hear. Res. 204, 60-77.

Nigg, B. M., and Herzog, W. (1999). Biomechanics of the Musculo-Skeletal System, 2nd ed. (Wiley, New York).

Northrop, C., Piza, J., and Eavey, R. D. (1986). "Histological observations of amniotic fluid cellular content in the ear of neonates and infants," Int. J. Pediatr. Otorhinolaryngol. 11, 113-127.

Olszewski, J. (1990). "Zur Morphometrie der Gehöknöchelchen beim Menschen im Rahmen der Entwicklung" ("The morphometry of the ear ossicles in humans during development"), Anat. Anz 171, 187-191.

Paradise, J. L., Smith, C. G., and Bluestone, C. D. (1976). "Tympanometric detection of middle ear effusion in infants and young children," Pediatrics 58, 198-210.

Qi, L., Liu, H., Lutfy, J., Funnell, W. R. J., and Daniel, S. J. (2006). “A non-linear finite-element model of the newborn ear canal," J. Acoust. Soc. Am. 120, 3789-3798. 
Ravicz, M. E., and Rosowski, J. J. (1997). "Sound-power collection by the auditory periphery of the Mongolian gerbil Meriones unguiculatus: III. Effect of variations in middle-ear volume," J. Acoust. Soc. Am. 101, 2135-2147.

Ravicz, M. E., Rosowski, J. J., and Voigt, H. F. (1992). "Sound-power collection by the auditory periphery of the Mongolian gerbil Meriones unguiculatus. I: Middle-ear input impedance," J. Acoust. Soc. Am. 92, 157-177.

Rollhauser, H. (1950). "Die Zugfestigkeit der Menschlichen Haut" ("The tensile strength of human skin"), Gegenbaurs Morphol. Jahrb 90, 249261.

Rosowski, J. J., and Lee, C. Y. (2002). "The effect of immobilizing the gerbil's pars flaccida on the middle-ear's response to static pressure,' Hear. Res. 174, 183-195.

Ruah, C. B., Schachern, P. A., Zelterman, D., Paparella, M. M., and Yoon, T. H. (1991). "Age-related morphologic changes in the human tympanic membrane. A light and electron microscopic study," Arch. Otolaryngol. Head Neck Surg. 117, 627-634.

Samani, A., and Plewes, D. (2004). "A method to measure the hyperelastic parameters of ex vivo breast tissue sample," Phys. Med. Biol. 49, 43954405 .

Sanford, C. A., and Feeney, M. P. (2007). "Energy reflectance tympanometry in infants," 30th Midwinter Res. Mtg., Assoc. Res. Otolaryngol., Denver.

Schmidt, S. H., and Hellstrom, S. (1991). "Tympanic-membrane structure new views. A comparative study," ORL 53, 32-36.

Schwarz, W. (1957). Connective Tissue (Blackwells, Oxford).

Shahnaz, N., Miranda, T., and Polka, L. (2008). "Multi-frequency tympanometry in neonatal intensive care unit and well babies," J. Am. Acad. Audiol, in press.

Shanks, J. E., and Lilly, D. J. (1981). "An evaluation of tympanometric estimates of ear canal volume," J. Speech Hear. Res. 24, 557-566.

Shanks, J. E., Wilson, R. H., and Cambron, N. K. (1993). "Multiple frequency tympanometry: Effects of ear canal volume compensation on static acoustic admittance and estimates of middle ear resonance," J. Speech Hear. Res. 36, 178-185.

Stepp, C. E., and Voss, S. E. (2005). "Acoustics of the human middle-ear air space," J. Acoust. Soc. Am. 118, 861-871.

Stoltz, J. F. (2006). Mechanobiology: Cartilage and Chondrocytes (IOS, Washington, DC), Vol. 4

Takahara, T., Sando, I., Hashida, Y., and Shibahara, Y. (1986). "Mesenchyme remaining in human temporal bones," Otolaryngol.-Head Neck Surg. 95, 349-357.

Unur, E., Ülger, H., and Ekinci, N. (2002). "Morphometrical and morphological variations of middle ear ossicles in the newborn," Erciyes Med. J. 24, 57-63 (http://tipdergisi.erciyes.edu.tr/project6/112.pdf, last viewed 2007 Dec 22).

von Unge, M., Decraemer, W. F., Bagger-Sjöbäck, D., and Dirckx, J. J. J. (1993). "Displacement of the gerbil tympanic membrane under static pressure variations measured with a real-time differential moire interferometer," Hear. Res. 70, 229-242.

Vorwerk, U., Steinicke, G., and Begall, K. (1999). "Observation of eardrum movements during quasi-static pressure changes by high-speed digital imaging," Audiol. Neuro-Otol. 4, 150-155.

Yamada, H. (1970). Strength of Biological Materials (Williams and Wilkins, Baltimore)

Yokoyama, T., Iino, Y., Kakizaki, K., and Murakami, Y. (1999). "Human temporal bone study on the postnatal ossification process of auditory ossicles," Laryngoscope 109, 927-930.

Zwislocki, J. (1962). "Analysis of the middle-ear function. 1. Input impedance," J. Acoust. Soc. Am. 34, 1514-1523. 